\title{
Operational definitions of paediatric asthma used in epidemiological studies: A systematic review
}

\author{
Mohammad Shahidul Islam ${ }^{1,4}$, \\ Samin $\mathrm{Huq}^{4}$, Salahuddin \\ Ahmed ${ }^{1,5}$, Sudipto Roy ${ }^{1,6}$, \\ Jürgen Schwarze ${ }^{2,3}$, Aziz \\ Sheikh ${ }^{1}$, Samir K Saha ${ }^{4}$, Steve \\ Cunningham ${ }^{2,3}$, Harish Nair'; \\ RESPIRE collaboration
}

\author{
${ }^{1}$ Usher Institute, College of Medicine \\ and Veterinary Medicine, University of \\ Edinburgh, UK \\ ${ }^{2}$ Child Life and Health, University of \\ Edinburgh, UK \\ ${ }^{3}$ Centre for Inflammation Research, \\ University of Edinburgh, UK \\ ${ }^{4}$ Child Health Research Foundation, \\ Dhaka, Bangladesh \\ ${ }^{5}$ Projahnmo Research Foundation, \\ Dhaka, Bangladesh \\ ${ }^{6} \mathrm{KEM}$ Hospital Research Centre, Pune, \\ India
}

\begin{abstract}
Background Researchers use different definitions to identify children with asthma in epidemiological surveys. We conducted a systematic review to describe the definitions used in epidemiologic studies for wheeze and asthma in the paediatric population, aimed to inform the development of a uniform definition of paediatric asthma for future epidemiological research.
\end{abstract}

Methods We systematically searched terms to identify asthma and/or wheeze among children aged <13 years and published between 1995-2020 across seven databases (MEDLINE, EMBASE, PsycINFO, Global Health, AMED, LILACS and CINAHL). PRISMA guidelines were followed for this review.

Results We extracted a total of 11886 records, where 190 met our eligibility criteria and included in the analysis. Among the included studies, $62.1 \%$ ( $n=118 / 190)$ used the International Study of Asthma and Allergies in Childhood (ISAAC) questionnaires, predominantly in developing countries (80\%, $\mathrm{n}=64 / 80$ ). 'Wheeze' was reported in five categories, subdivided by 14 different definitions. "Current wheeze", defined as caregivers report of wheezing sounds from the chest of the child in the past 12 months and "Wheeze ever", defined as caregivers' report of wheezing or whistling in the chest of the child at any previous time, were the most common wheeze category reported in 129 and 95 studies, respectively. Asthma was reported in nine categories using 53 definitions. The most common asthma category was "Asthma ever", which was reported in 89 studies, based on caregiver statement that the child had asthma in the past.

Conclusion Definitions of wheeze and asthma for children used in surveys are primarily based on parent-reported clinical features. Studies from developing countries more frequently used the ISAAC definitions to report childhood asthma and wheeze compared to the studies from developed counties. The use of a uniform asthma definition will aid the interpretation of research findings globally.

Asthma is a common chronic lung disease affecting approximately $12 \%$ of children aged 6-7 years globally [1] and characterised by narrow bronchial airways causing airway obstruction [2]. The definition and classification of asthma have been continuously reviewed and updated with new information due to the variability of signs and symptoms [3]. Still, an accurate diagnosis of asthma remains a challenge, particularly for children, as it presents different phenotypes depending on the child's age, gender, and ethnicity [4,5]. 
There is no standard definition of the type, severity, or frequency of symptoms that define childhood asthma [6], making it difficult to ascertain asthma diagnoses using an evidence-based definition. Objective measurements, such as airflow limitation or airway inflammation, the two primary biological parameters of asthma, are difficult to assess in young children as they require patient cooperation [7]. Thus, only a few population-based studies in children have applied objective measurement to identify asthma cases in children [8,9]. Instead, researchers often use operational definitions of asthma, primarily based on parental response to a set of questionnaires developed by the International Study of Asthma and Allergies in Childhood (ISAAC) $[9,10]$. These operational definitions of childhood asthma directly impact the estimated disease burden and may complicate asthma epidemiology studies. Besides, the use of inconsistent case definitions for asthma surveillance may lead to inaccurate estimations of disease burden, creating difficulty when formulating appropriate asthma prevention policies [11]. Development of a standardised and well-accepted case definition of asthma with high sensitivity and specificity would help in achieving accurate determination of disease burden, international comparisons and formulation of effective prevention and disease control policy.

Therefore, we systematically interrogated the operational definitions of childhood asthma used in epidemiological studies to inform the development of a uniform definition of paediatric asthma for future epidemiological research.

\section{METHODS}

We conducted this review following the Arksey and O'Malley five-stage framework, including identifying the research question, identifying the relevant studies, study selection, data extraction, and collation, summarising and reporting the results [12]. Our research question for this review was: "what are the different case definitions for the diagnosis of childhood asthma that were used in epidemiological studies?"

We identified the relevant studies by searching seven electronic databases: MEDLINE (Ovid), EMBASE (Ovid), PsycINFO (Ovid), Global Health (Ovid), AMED (Ovid), LILACS and CINAHL (EBSCO). We also reviewed the citations of the included studies to ensure that all relevant studies were included.

\section{Eligibility criteria \& search strategies}

We explored research articles mainly in two domains: i) articles reporting asthma and/or wheeze, and ii) articles on children. During database searching, we looked for observational studies published between 1 January 1995 and 31 December 2020. We iteratively improved the search strategy by adding variations and equivalents of the keyword "asthma" and "children. Table S1 in the Online Supplementary Document provides search terms and searches outcomes.

\section{Study selection and assessment of the methodological quality}

We followed the PRISMA guidelines for study selection [13]. We removed the duplicates in our database searches, and three reviewers (SA, SH and MSI) reviewed the titles and abstracts of articles identified. We subsequently reviewed the full-texts of selected articles and extracted data from studies meeting our eligibility criteria. Two reviewers (MSI and SA) independently checked the full text of the selected articles to determine whether they met all eligibility criteria with a third author arbitrating $(\mathrm{SH})$. If more than one article presented similar outcomes and exposure at a similar age in the same cohort, then only one article that provided more epidemiological information was included in the analysis. The following eligibility criteria were used to include articles of epidemiological studies for review: i) publication year between 1 January 1995 and 31 December 2020, ii) age of the participants below 13 years, iii) asthma as the primary outcome reported, iv) the full text was available in English, v) disease was described among human subjects, and vi) included (sample size) at least one hundred participants. We applied the Newcastle-Ottawa Quality Assessment Scale (NOS) to assess the methodological quality of the selected articles [14].

\section{Data extraction and analysis}

We followed the Methodological Expectations of Cochrane Intervention Reviews (MECIR) guidelines for data collection [15]. We extracted the following information: region, country, settings (rural or urban), study design, age and sex of the participants, year of data collection and reporting, who provided the information, data sources, case definitions used to identify asthma patients, disease condition, number of study participants included in the studies and total number of cases identified under each disease condition. We extracted information for the most recent year from the articles that published data at different time points. We coded any 
response value in the text (eg, sex, study design, settings, disease condition, etc.). The primary aim of data analysis was to identify the different case definitions used to describe asthma phenotypes. We extracted the precise case definitions used in the studies and grouped them into two categories: i) asthma and ii) wheeze, which was further subcategorised. We estimated the asthma disease prevalence based on the studies' definitions to assess their impact on asthma case identification. We presented the data both in numbers and percentage wherever suitable. We assessed the amount of heterogeneity between the studies assessed using $I^{2}$. Anticipating substantial heterogeneity, we decided to use a random-effects model. We used United Nations Human Development Index 2020 to categorise the countries by economic development [16]. We used Statistics and Data Science (StataCorp LLC, College Station, Texas, USA) version 14 to perform the analysis.

\section{Risk of bias assessment}

We used the Newcastle-Ottawa scale (NOS) to assess the risk of bias (ROB) in the included articles. We provide a maximum score of nine points ( 4 for 'Selection, 2 for 'Comparability' and 3 for 'Outcome') spread across three domains [14]. Scoring was undertaken independently by two reviewers, with a third reviewer resolving any disagreements. Studies were considered at low ROB when the overall scores were 8-9; medium ROB when scores were 6-7; and high when the ROB scores were 0-5.

\section{Role of the funding source}

The funder had no role in study design, data collection, analysis and interpretation of data, report writing, or the decision-making process to submit the paper for publication.

\section{RESULTS}

We included 190 articles from 190 different studies in this systematic review (Figure 1, Table S2 in the Online Supplementary Document). One hundred and three studies (54.2\%) included urban population, 23 studies (12.1\%) included rural populations, and 64 studies (36.7\%) included both urban and rural populations (Table 1). Although the selected studies represent all the major geographic regions, the majority were from the European region $(n=74,39.4 \%)$, followed by the Americas region $(n=43,22.9 \%)$ (Table 1, Figure 2$)$. Among the 190 studies, 158 studies were cross-sectional studies, and 17 were birth-cohort studies (Table 1). One hundred and eighteen studies (62.1\%) used ISAAC questionnaires, and 58 studies (30.5\%) used study-specific questionnaires, and the remaining 14 studies (7.4\%) studies used electronic medical records and other sources (Table 1). ISAAC questionnaires were used in $80.0 \%$ of studies $(n=64 / 80)$ conducted in developing countries, compared to only 49.1\% ( $n=54 / 110)$ studies from the developed part of the world. Only three studies have added

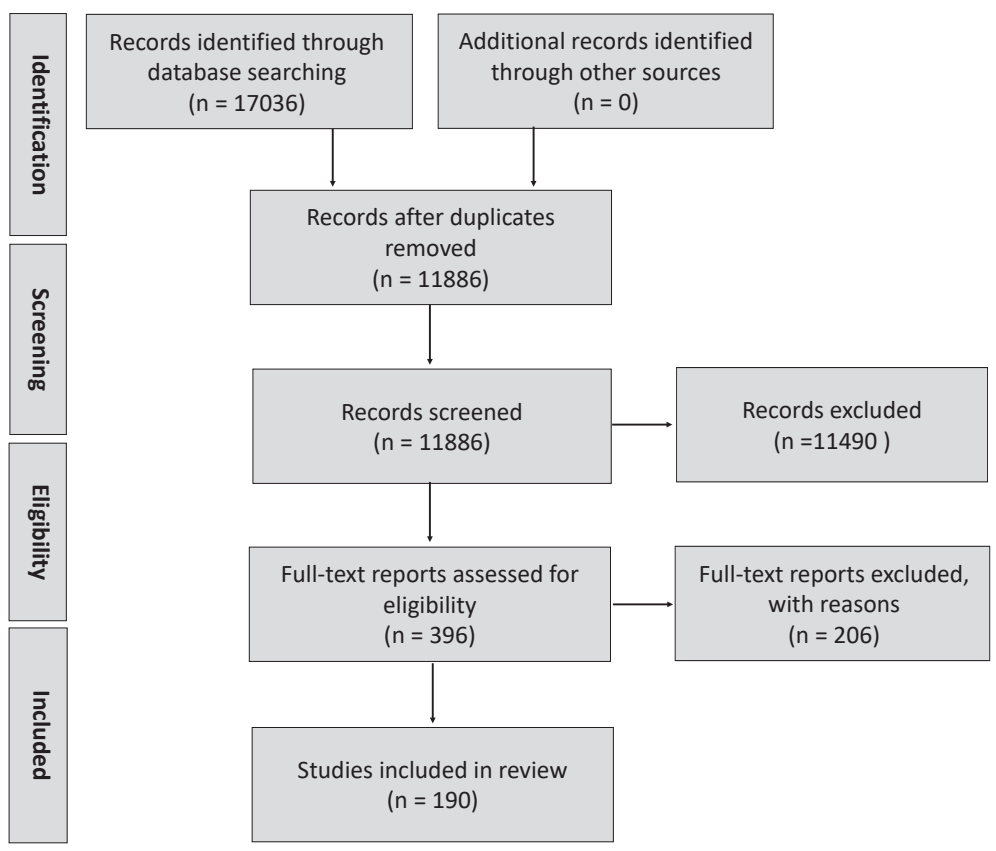

Figure 1. Study selection process for reviewing the definitions of paediatric asthma used in epidemiological studies. a pulmonary function test in their asthma definitions $[17,18]$. Ninety-three percent $(n=177 / 190)$ studies collected information from caregivers, and $73.7 \%(\mathrm{n}=140 / 190)$ studies included 6-12 years age children (Table 1). Intra-study ROB ranged from 5 to 9 , with a mean score of 7.2 , showing a generally low risk of bias across the studies. The mean scores across each domain of NOS scale were: 1.6 out of a possible score of 2 points for 'comparability'; 3.8 out of 5 for 'selection'; and 1.6 out of 3 for 'outcome.'

\section{Operational definitions of asthma}

Asthma prevalence was reported in two broad groups: wheeze and asthma (Table 2). Wheeze was reported in 146 articles under five distinct categories: "Wheeze ever", "Current wheeze", "Exercise-induced wheeze", "Persistent wheezer", and "Infant wheezer" (Table 2). "Wheeze ever" was reported in 95 articles when the children had a wheezing history. For this category, wheezing or whistling in the chest at any time in the past was used in 94 articles (Table S3 in the Online Supple- 
Table 1. Characteristics of the selected studies included in the systemic review of the operational definitions of paediatric asthma used in epidemiological studies $(n=190)$

\begin{tabular}{|c|c|}
\hline STUDY CHARACTERISTICS & NUMBER OF STUDIES (\%) \\
\hline \multicolumn{2}{|l|}{ Settings: } \\
\hline Rural & $23(12.1)$ \\
\hline Urban & $103(54.2)$ \\
\hline Both & $64(33.7)$ \\
\hline \multicolumn{2}{|l|}{ Geographic regions: } \\
\hline African Region & $5(2.7)$ \\
\hline Eastern Mediterranean Region & $25(13.1)$ \\
\hline European Region & $75(39.5)$ \\
\hline Region of the Americas & $43(22.6)$ \\
\hline South-East Asia Region & $7(3.7)$ \\
\hline Western Pacific Region & $35(18.4)$ \\
\hline \multicolumn{2}{|l|}{ Country economic status: } \\
\hline Developing economies & $80(42.1)$ \\
\hline Developed economies & $110(47.9)$ \\
\hline \multicolumn{2}{|l|}{ Type of studies: } \\
\hline Cross-sectional/prevalence study & $158(83.2)$ \\
\hline Retrospective cohort study & $6(3.2)$ \\
\hline Longitudinal cohort study & $4(2.1)$ \\
\hline Nested cohort study & $3(1.6)$ \\
\hline Prospective birth cohort study & $17(9.0)$ \\
\hline Randomized controlled trial & $1(0.5)$ \\
\hline Case-control study & $1(0.5)$ \\
\hline
\end{tabular}

STUDY CHARACTERISTICS

NUMBER OF STUDIES (\%)

Data source:

\begin{tabular}{lc}
\hline ISAAC standardized questionnaire & $118(62.1)$ \\
\hline Study-specific Questionnaire & $58(30.5)$ \\
\hline Medical records & $6(3.2)$ \\
\hline Health insurance claims & $1(0.5)$ \\
\hline Web-based Survey & $1(0.5)$ \\
\hline Telephone survey & $3(1.6)$ \\
\hline Interview & $1(0.5)$ \\
\hline Mixed (questionnaire \& clinical assessment) & $2(1.1)$ \\
\hline Respondent types: & $177(93.2)$ \\
\hline Mother/parents & $4(2.1)$ \\
\hline Children & $4(2.1)$ \\
\hline Studyteam Members & $5(2.6)$ \\
\hline Unknown & $26(13.6)$ \\
\hline Age categories (years): & $140(73.7)$ \\
\hline $0-5$ & $24(12.6)$ \\
\hline $6-12$ &
\end{tabular}

ISAAC - The International Study of Asthma and Allergies in Childhood

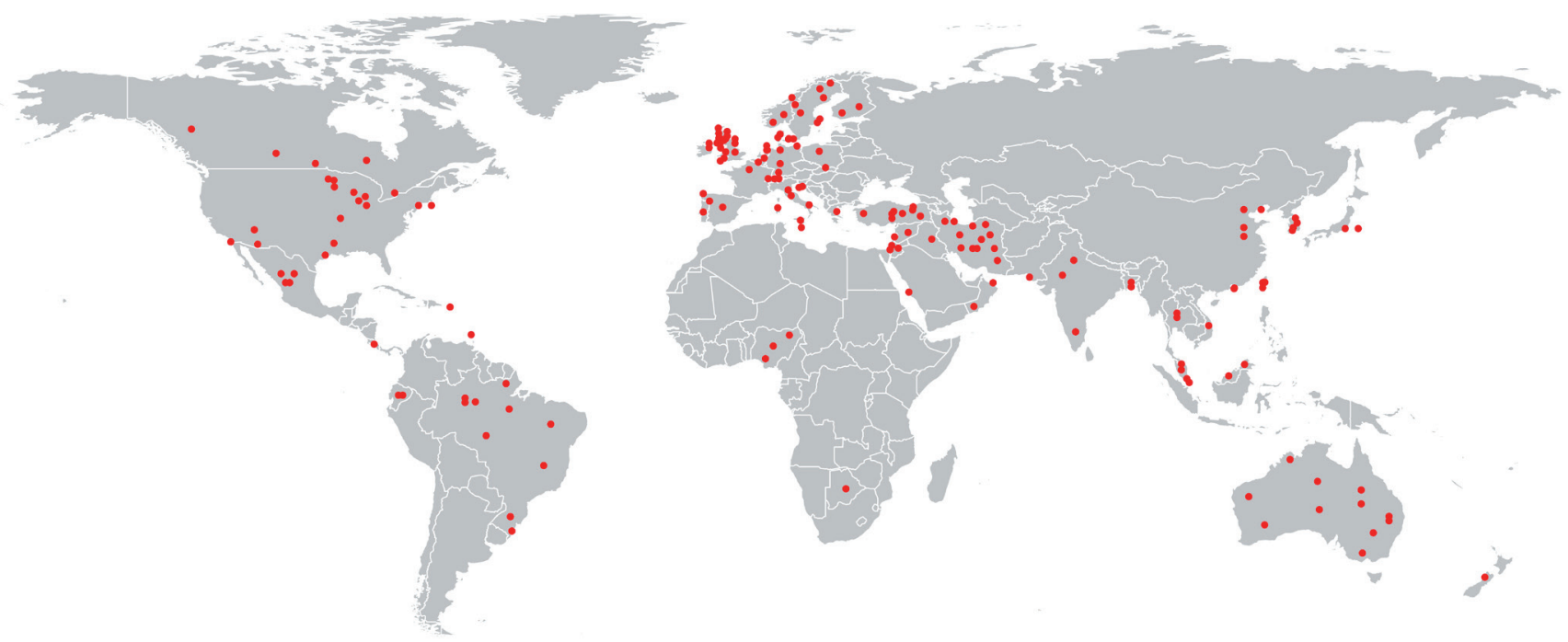

Figure 2. Geographical location of data collection for the selected studies used to review paediatric asthma definitions.

mentary Document) [19-23]. Children with a wheezing history in the previous 12 months were categorised as "Current wheeze" in 129 articles using eight definitions based on the frequency of wheezing episodes and additional symptoms (Table S3 in the Online Supplementary Document) [24-27]. "Exercise-induced wheeze" was reported in 49 articles using the same criterion (children who developed wheeze after exercise) (Table S3 in the Online Supplementary Document) [28-31]. Two articles used "Persistent wheezing" for children who had repeated wheeze episodes for an extended period (Table S3 in the Online Supplementary Document) [32]. Children aged less than two with a wheezing history were categorised as "Infant wheezers" in one article (Table S3 in the Online Supplementary Document) [33].

Asthma was reported in 180 articles in nine categories (Table 2). Children with a history of asthma were reported as "Asthma ever" in 89 articles. We found ten definitions for "Asthma ever", primarily based on parental reports, physician diagnosis, or recorded in medical records (Table S4 in the Online Supplementary 
Table 2. Number of identified definitions used to define different type of asthma and wheeze in epidemiological studies

\begin{tabular}{|c|c|c|}
\hline $\begin{array}{l}\text { CATEGORY AND } \\
\text { SUB-CATEGORIES }\end{array}$ & $\begin{array}{l}\text { NUMBER OF IDENTIFIED } \\
\text { DEFINITIONS }\end{array}$ & $\begin{array}{c}\text { NUMBER OF STUDIES } \\
\text { REPORTED (\%) }\end{array}$ \\
\hline \multicolumn{3}{|l|}{ Wheeze: } \\
\hline Wheeze ever & 2 & $95(50)$ \\
\hline Current wheeze & 8 & $129(67.9)$ \\
\hline Exercise-induced wheeze & 1 & $49(25.8)$ \\
\hline Persistent wheezing & 2 & $2(1.0)$ \\
\hline Infant wheezer & 1 & $1(0.5)$ \\
\hline \multicolumn{3}{|l|}{ Asthma: } \\
\hline Asthma ever & 10 & $89(46.8)$ \\
\hline Current asthma & 25 & $55(28.9)$ \\
\hline Doctor-diagnosed asthma & 5 & $76(40.0)$ \\
\hline Diagnosed-asthma & 2 & $2(1.1)$ \\
\hline Asthma-like syndrome & 4 & $3(1.6)$ \\
\hline Probable asthma & 3 & $3(1.6)$ \\
\hline Past asthmatics & 2 & $2(1.0)$ \\
\hline Persistent asthma & 2 & $2(1.0)$ \\
\hline Possible asthma & 1 & $1(0.5)$ \\
\hline
\end{tabular}

Document [34-38]. Children with a recent episode of an asthma attack were categorised as "Current asthma" in 53 articles, and we found 25 different definitions for this disease condition (Table S4 in the Online Supplementary Document) [39-43]. Children who had asthma confirmed by a physician at any previous time point were categorised as "Doctor-diagnosed asthma" in 76 articles, and five different definitions were used for this disease condition (Table S4 in the Online Supplementary Document) [44-48]. Children who had asthma determined by objective measurement were categorised as "Diagnosed-asthma" in two articles (Table S4 in the Online Supplementary Document) [49]. Children with respiratory symptoms similar to asthma were categorised as "Asthma-like syndrome" in five articles with five different definitions (Table S4 in the Online Supplementary Document) $[50,51]$. Children with asthma signs or symptoms which was not confirmed by a physician were categorised as "Probable Asthma" in three articles using three different definitions (Table S4 in the Online Supplementary Document) [52]. Children with a history of asthma with no symptoms during the last 12 months were defined as "Past asthma" in two articles using two definitions (Table S4 in the Online Supplementary Document) [53]. "Persistent asthma" was reported in two articles for those children who had frequent asthma attacks for a longer period (Table S3 in the Online Supplementary Document) [54].

\section{Regional variation in reporting asthma}

We found a significant difference in the reporting of asthma disease prevalence in different World Health Organisation regions. "Wheeze ever" was reported in $60 \%$ of articles published in the African region $(n=3 / 5)$, compared to $76 \%(n=19 / 25)$ in the Eastern Mediterranean region, 57.1\% ( $n=20 / 35)$ in the Western Pacific region, $57 \%(n=4 / 7)$ in the South-East Asian region, $42.6 \%(n=32 / 75)$ in the European region, and $39.5 \%$ $(n=17 / 43)$ in the Americas region.

"Current wheeze" was reported in 80\% ( $n=4 / 5)$ articles from African region, $72.0 \%(n=18 / 25)$ from the Eastern Mediterranean region, 82.9\% $(n=29 / 35)$ from the Western Pacific region, $57.1 \%(n=4 / 7)$ from the South-East Asian region, 65.3\% ( $n=49 / 75)$ from the European region, and 58.1\% ( $n=25 / 43)$ from the Americas region.

"Asthma ever" was reported in 40\% ( $n=2 / 5)$ studies from African region, 60.0\% ( $n=15 / 25)$ from the Eastern Mediterranean region, 45.7\% $(n=16 / 35)$ from the Western Pacific region, $29.0 \%(n=2 / 7)$ from the South-East Asian region, 45.1\% ( $n=34 / 75)$ from the European region, and 46.5\% ( $n=20 / 43)$ from the Americas region.

Globally, only 28.9\% of the selected studies reported "Current asthma" predominantly from the European Region $(42.6 \%, n=32 / 75)$. Still, only in $8.0 \%(n=2 / 25)$ of the studies from the Eastern Mediterranean region, $25.7 \%(n=9 / 35)$ studies from the Western Pacific region, 28.0\% ( $n=2 / 7)$ from the South-East Asian region, $23.3 \%(n=10 / 43)$ from the Americas region reported this disease condition. None of the five articles published in the Africa region reported "Current asthma".

"Doctor-diagnosed asthma" was reported in 40.0\% ( $\mathrm{n}=76 / 190)$ of studies: in $80.0 \%(\mathrm{n}=4 / 5)$ of studies from Africa region, 40.0\% ( $n=10 / 25)$ from the Eastern Mediterranean region, 45.7\% ( $n=16 / 35)$ from the Western Pacific region, 28.5\% ( $n=2 / 7)$ from the South-East Asian region, 40.0\% ( $n=30 / 75)$ from the European region, and $32.5 \%(n=14 / 43)$ from the Americas region. Other asthma categories were reported in less than 5\% of studies, mostly from the studies conducted in Europe and the Americas regions.

\section{Asthma prevalence by definitions}

We found "Wheeze ever" as the most prevalent asthma disease category across all regions (Figure 3). Our estimated global prevalence of wheeze ever was 24.0\% (95\% confidence interval $(\mathrm{CI})=21.9-26.1)$ and ranged 

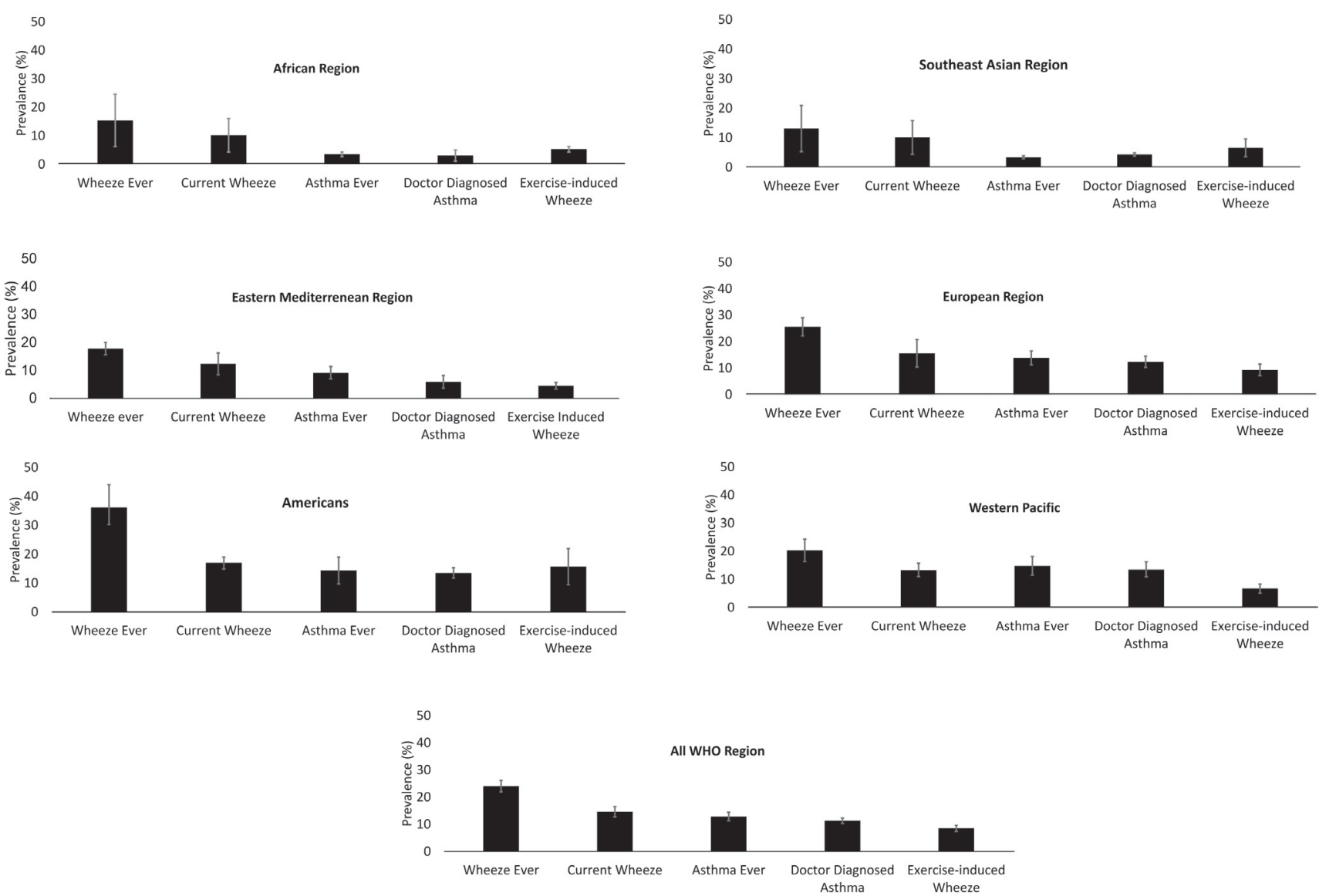

Figure 3. Regional distribution of asthma prevalence in children aged $<13$ years.

between $13.1 \%(95 \% \mathrm{CI}=5.3-20.9)$ in the South-East Asia region to $36.2 \%(95 \% \mathrm{CI}=30.2-44.8)$ in the Amer-icas region. The overall prevalence of "Current wheeze" was 14.6\% (95\% CI $=12.7-16.5)$ and ranging between $10.1 \%$ (95\% CI $=4.4-15.8)$ in the South-East Asia region to $17.0 \%(95 \% \mathrm{CI}=14.9 \%-19.0 \%)$ in the Americas region. The overall prevalence of "Exercise-induced wheeze" was 8.5\% (95\% CI=7.4\%-9.6\%); the lowest was in the Eastern Mediterranean region $(4.5 \%, 95 \% \mathrm{CI}=3.3 \%-5.7 \%$ ) and highest in the Americans region $(15.7 \%, 95 \% \mathrm{CI}=9.4 \%-21.9 \%)$.

The overall prevalence of "Asthma ever" was 12.8\% (95\% CI=15.3\%-20.4\%) (Figure 3); the lowest being in the South-East Asian region (3.4\%, 95\% CI=2.9\%-3.9\%) and highest in the Western Pacific region (14.8\%, 95\% CI $=11.5 \%-18.1 \%$ ). The prevalence of "Doctor-diagnosed asthma" was $11.3 \%$ (95\% CI=10.3\%-12.3\%), and ranging 3.1\% (95\% CI=1.1\%-5.0\%) in African region to 13.3\% (95\% CI=11.7\%-15.3\%) in the Americas region.

\section{DISCUSSION}

We found extensive research on childhood asthma in the past three decades globally. We analysed 190 articles published between 1995 and 2020, representing all regions of the World Health Organisation (WHO). We found 64 definitions, mostly from developed countries using distinct asthma phenotypes to define various asthma types in children; however, objective information from clinical measurements was incorporated only in very few of these definitions. This could be due to the considerable influence of ISAAC (a global initiative established in 1991 to investigate asthma, rhinitis, and eczema in children) in asthma research over the past three decades. Over $50 \%$ of the studies included in this review used ISAAC definitions of asthma. The ISAAC research methodologies for evaluating childhood asthma and wheezing were constructed on questionnaire-based responses from the caregivers. Such preference could be linked with its suitability to conduct research at a low cost and with a limited skilled workforce. Despite some limitations, the ISAAC initiative provides strong evidence for the feasibility of developing an optimal universal definition to diagnose childhood asthma at the community level. 
On the contrary, we have identified a wide range of definitions for childhood asthma. The maximum variance was found in the definitions of "Current asthma" and "Current wheeze". Researchers used 25 distinct definitions for childhood "Current asthma" and eight definitions for "Current wheeze". This variation was due to the use of different time cut-offs and criteria to evaluate and diagnose current asthma. Disease episode during the past 12 months was used to report "Current asthma" ( $n=41 / 53)$ and "Current wheeze" ( $n=126 / 129)$ in most of the studies. Nevertheless, three studies defined "Current wheeze" using a period of 3 years $[55,56]$, and 16 studies reported "Current wheeze" without mentioning a specific time period. We also observed a significant disparity in determining "Asthma ever", which was largely constructed from the parental statement of their children of ever having asthma, either alone or in combination with diagnosis confirmed by a doctor. However, we have observed a consensus in defining "Wheeze ever"; this condition was unanimously defined based on the parental reporting of wheeze or wheezing sound in the chest of their child.

We found only three studies that used pulmonary function test to diagnose asthma [57-59]. However, different guidelines have emphasised using objective assessments, the limitations in the diagnosis of asthma using medical history and physical examination - as a non-reliable means of excluding other diagnoses or of characterising the status of lung impairment [60-62]. Resource scarcity, lack of available expertise in the community and poor patient compliance might be reasons for the low uptake of objective measurement in asthma surveys [63].

We have also estimated the overall prevalence of different asthma diseases conditions and found that the asthma disease burden changes profoundly based on the diagnostic definition used. The reported prevalence of "Wheeze ever" (24.0\%) was about twice as high as the prevalence reported for "Asthma ever" (12.8\%). This variance in asthma prevalence has a significant public health implication - since the uptake of policy decisions to control or prevent a particular disease largely depend on existing disease prevalence in the area.

To the best of our knowledge, this is the first attempt to systematically investigate the operational definitions used in epidemiological studies in the context of childhood asthma. We used a robust approach for this review that involved multiple researchers independently identifying studies and compared. All data were extracted at least by two researchers. To be inclusive, we have explored seven relevant databases and included studies published in the last 26 years from all geographic regions. As per the NOS criteria, our included articles had a low risk of bias with a mean score of seven out of nine. A potential limitation of this systematic review is that we had to exclude several articles as some of the study subjects did not meet the age limit for this review. Additionally, we could not assess the impact of individual criteria on disease burden estimates as some definitions were used in very few studies.

This review demonstrates a huge research gap in childhood asthma research by economic development. The majority of the included articles ( $\mathrm{n}=118,62 \%$ ) were published from the European and American regions that mostly represent the developed part of the world. Only 12 (6\%) included articles published from South East Asia and African regions, representing most of the least developed countries of the world.

The variety of definitions identified in this systematic review illustrates the challenges of establishing an internationally accepted epidemiological definition to measure childhood asthma. Through this review, we have identified a range of asthma definitions, which primarily relied on parent-reported clinical symptoms. We also found that researchers did not use these definitions systematically, and the same definitions were used differently on many occasions. For example, in some studies, researchers diagnosed asthma based on the caregiver statement of a wheezing episode in the previous 12 months, but that definition was mostly used to report "Current wheeze" in other studies [64,65]. Additionally, some definitions were used in different combinations in different studies [66-69].

During the last few decades, there has been little improvement in asthma outcomes despite significant progress in hospitalisation due to a lack of appropriate disease diagnosis. The diagnosis of asthma based on the clinical features and without objective measurement might result in substantial uncertainties in the disease burden and might boost poor asthma management. A recent review of diagnostic accuracy of respiratory diseases in primary health units demonstrated a poor record for asthma diagnosis among the practitioners. The report also found that up to $74 \%$ of asthma cases were over-diagnosed in primary health care centres [70]. Further, a prospective multicentre study in Canada failed to diagnose asthma in $33.1 \%$ of adults with physician-diagnosed asthma who were not using daily asthma medications or had medications weaned [71]. Therefore, the Lancet Commission on asthma (2017) recommends deconstructing airway disease into component parts for greater precision in asthma diagnosis through the use of spirometry and other (eg, eosinophil count) measures [72]. We re-emphasise the Lancet Commission recommendations as proper diagnosis of asthma using objective measurements both in children and adults are important for patient care as well as for making strategic decisions 
Box 1. Recommendation for future reporting of asthma disease burden estimation

- Should demonstrate a minimum set of criteria in any asthma disease burden estimation among children which should include the prevalence of history of recurrent wheeze and asthma.

- Should avoid using customised definition of asthma for disease burden estimation.

- Should not amalgamate the definitions available in various guidelines.

- Should use the validated research methodologies in asthma disease burden estimation

- Should use at least one lung function test to confirm the ongoing asthma.

- Should conduct any clinical assessment by medically trained research staff. to reduce the disease burden. Additionally, we recommend the following items listed in Box 1 while reporting asthma disease burden. We believe that a global initiative to establish accurate childhood asthma measurements will improve prevalence estimation accuracy in future epidemiological asthma surveys. At present, we are doing a feasibility study of using portable spirometers to measure the pulmonary function of children age less than eight years in resource-poor settings. Successful use of our research methodologies will encourage the global community to include such techniques in future asthma disease survey.

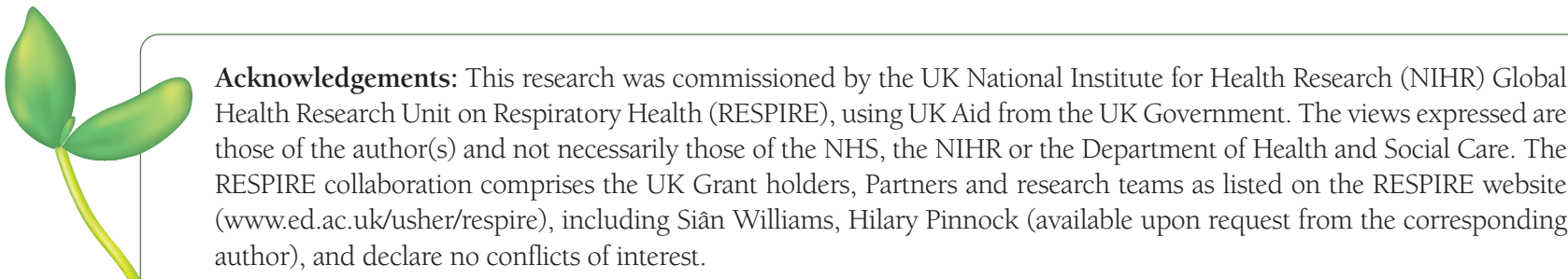

Disclaimer: The views expressed in the submitted article are those of the authors' own and not an official position of the institution or funder.

RESPIRE collaborations: Prof. Hilary Pinnock (NIHR Global Health Research Unit on Respiratory Health (RESPIRE), Usher Institute, The University of Edinburgh), Prof. Harish Nair (NIHR Global Health Research Unit on Respiratory Health (RESPIRE), Usher Institute, The University of Edinburgh, Prof Aziz Sheikh (NIHR Global Health Research Unit on Respiratory Health (RESPIRE), Usher Institute, The University of Edinburgh), Prof Harry Campbell (NIHR Global Health Research Unit on Respiratory Health (RESPIRE), Usher Institute, The University of Edinburgh).

Authorship contributions: MSI performed database searches, SA, MSI and SR screened the title and abstract, SH and MSI reviewed the studies and extracted the data, AZ, JS, HN, SKS and SC contributed substantially to the conception, design and writing of the paper. MSI performed the data analysis. All authors have read and approved the final manuscript.

Competing interests: The authors completed the ICMJE Unified Competing Interest form (available upon request from the corresponding author), and declare no conflicts of interest.

Additional material

Online Supplementary Document

1 Pearce N, Ait-Khaled N, Beasley R, Mallol J, Keil U, Mitchell E, et al. Worldwide trends in the prevalence of asthma symptoms: phase III of the International Study of Asthma and Allergies in Childhood (ISAAC). Thorax. 2007;62:758-66. Medline:17504817 doi:10.1136/thx.2006.070169

2 Bateman ED, Hurd SS, Barnes PJ, Bousquet J, Drazen JM, Fitzgerald JM, et al. Global strategy for asthma management and prevention: GINA executive summary. Eur Respir J. 2008;31:143-78. Medline:18166595 doi:10.1183/09031936.00138707

3 Terminology, definitions, and classification of chronic pulmonary emphysema and related conditions. Thorax. 1959;14:286. doi:10.1136/thx.14.4.286

4 Bakirtas A. Diagnostic challenges of childhood asthma. Curr Opin Pulm Med. 2017;23:27-33. Medline:27801711 doi:10.1097/ MCP.0000000000000338

5 Herzog R, Cunningham-Rundles S. Pediatric asthma: Natural history, assessment, and treatment. Mt Sinai J Med. 2011;78:64560. Medline:21913196 doi:10.1002/msj.20285

6 Guilbert TW, Bacharier LB, Fitzpatrick AM. Severe asthma in children. J Allergy Clin Immunol Pract. 2014;2:489-500. Medline:25213041 doi:10.1016/j.jaip.2014.06.022

7 Jat KR. Spirometry in children. Prim Care Respir J. 2013;22:221-9. Medline:23732636 doi:10.4104/pcrj.2013.00042

8 Remes ST, Pekkanen J, Remes K, Salonen R, Korppi M. In search of childhood asthma: questionnaire, tests of bronchial hyperresponsiveness, and clinical evaluation. Thorax. 2002;57:120-6. Medline:11828040 doi:10.1136/thorax.57.2.120

9 Sá-Sousa A, Jacinto T, Azevedo LF, Morais-Almeida M, Robalo-Cordeiro C, Bugalho-Almeida A, et al. Operational definitions of asthma in recent epidemiological studies are inconsistent. Clin Transl Allergy. 2014;4:24. Medline:25136441 doi:10.1186/20457022-4-24

10 Asher MI, Keil U, Anderson HR, Beasley R, Crane J, Martinez F, et al. International Study of Asthma and Allergies in Childhood (ISAAC): rationale and methods. Eur Respir J. 1995;8:483-91. Medline:7789502 doi:10.1183/09031936.95.08030483 
11 Desalu OO, Sanya EO, Adeoti AO, Aderibigbe SA, Kolo PM. Impact of Operational Definitions on the Predictors and Prevalence of Asthma Estimates: Experience from a University Students' Survey and Implications for Interpretation of Disease Burden. Ethiop J Health Sci. 2018;28:725-34. Medline:30607089

12 Arksey H, O’Malley L. Scoping studies: towards a methodological framework. Int J Soc Res Methodol. 2005;8:19-32. doi:10.1080/1364557032000119616

13 Liberati A, Altman DG, Tetzlaff J, Mulrow C, Gøtzsche PC, Ioannidis JP, et al. The PRISMA statement for reporting systematic reviews and meta-analyses of studies that evaluate health care interventions: explanation and elaboration. J Clin Epidemiol. 2009;62:e1-34. Medline:19631507 doi:10.1016/j.jclinepi.2009.06.006

14 Peterson J, Welch V, Losos M, Tugwell P. The Newcastle-Ottawa scale (NOS) for assessing the quality of nonrandomised studies in meta-analyses. Ottawa: Ottawa Hospital Research Institute. 2011.

15 Jackie Chandler RC. Julian Higgins, Toby Lasserson and David Tovey. Methodological standards for the conduct of new Cochrane Intervention Reviews. Methodological Expectations of Cochrane Intervention Reviews (MECIR) 2011.

16 Programme UND. Human Development Report 2020: United Nations; 2020.

17 Marks GB, Mihrshahi S, Kemp AS, Tovey ER, Webb K, Almqvist C, et al. Prevention of asthma during the first 5 years of life: a randomised controlled trial. J Allergy Clin Immunol. 2006;118:53-61. Medline:16815138 doi:10.1016/j.jaci.2006.04.004

18 Martyn M, Weaver AL, Jacobson RM, Juhn YJ. Characterisation of the duration from onset of asthma symptoms to asthma disease. Ann Allergy Asthma Immunol. 2008;100:589-95. Medline:18592824 doi:10.1016/S1081-1206(10)60059-2

19 Aberle N, Kljaić Bukvić B, Blekić M, Vučković M, Bardak D, Gudelj A, et al. Allergic diseases and atopy among schoolchildren in eastern Croatia. Acta Clin Croat. 2018;57:82-90. Medline:30256014 doi:10.20471/acc.2018.57.01.09

20 Hesselmar B, Åberg N, Åberg B, Eriksson B. Asthma in children: prevalence, treatment, and sensitisation. Pediatr Allergy Immunol. 2000;11:74-9. Medline:10893008 doi:10.1034/j.1399-3038.2000.00070.x

21 Nelson KA, Meadows L, Yan Y, Schootman M, Strunk RC. Asthma prevalence in low-income urban elementary school students in St. Louis, 1992 and 2004. J Pediatr. 2009;154:111-5. Medline:18760422 doi:10.1016/j.jpeds.2008.07.017

22 Quah BS, Mazidah AR, Hamzah AM, Simpson H. Prevalence of wheeze, night cough and doctor-diagnosed asthma in preschool children in Kota Bharu. Asian Pac J Allergy Immunol. 2000;18:15. Medline:12546053

23 Soto-Martínez ME, Yock-Corrales A, Camacho-Badilla K, Abdallah S, Duggan N, Avila-Benedictis L, et al. The current prevalence of asthma, allergic rhinitis, and eczema related symptoms in school-aged children in Costa Rica. J Asthma. 2019;56:3608. Medline:29693462 doi:10.1080/02770903.2018.1455860

24 Arshad SH, Kurukulaaratchy RJ, Fenn M, Matthews S. Early life risk factors for current wheeze, asthma, and bronchial hyperresponsiveness at 10 years of age. Chest. 2005;127:502-8. Medline:15705988 doi:10.1378/chest.127.2.502

25 Branco PT, Nunes R, Alvim-Ferraz M, Martins F, Ferraz C, Vaz L, et al. Asthma prevalence and risk factors in early childhood at Northern Portugal. Rev Port Pneumol. 2016;22:146-50. Medline:26747645 doi:10.1016/j.rppnen.2015.11.001

26 de Korte-de Boer D, Mommers M, Gielkens-Sijstermans C, Creemers H, Mujakovic S, Feron F, et al. Stabilising prevalence trends of eczema, asthma and rhinoconjunctivitis in Dutch schoolchildren (2001-2010). Allergy. 2015;70:1669-73. Medline:26289999 doi:10.1111/all.12728

27 McCann D, McWhirter J, Coleman H, Devall I, Calvert M, Weare K, et al. The prevalence and management of asthma in primary-aged schoolchildren in the south of England. Health Educ Res. 2002;17:181-94. Medline:12036234 doi:10.1093/ her/17.2.181

28 Banac S, Lah Tomulić K, Ahel V, Rozmanić V, Simundic N, Zubovic S, et al. Prevalence of asthma and allergic diseases in Croatian children is increasing: survey study. Croat Med J. 2004:45:721-6. Medline:15578806

29 Duhme H, Weiland S, Rudolph P, Wienke A, Kramer A, Keil U. Asthma and allergies among children in West and East Germany: a comparison between Munster and Greifswald using the ISAAC phase I protocol. International Study of Asthma and Allergies in Childhood. Eur Respir J. 1998;11:840-7. Medline:9623686 doi:10.1183/09031936.98.11040840

30 López-Silvarrey-Varela A, Pértega-Díaz S, Rueda-Esteban S, Sánchez-Lastres JM, San-José-González MA, Sampedro-Campos $\mathrm{M}$, et al. Prevalence and geographic variations in asthma symptoms in children and adolescents in Galicia (Spain). Arch Bronconeumol. 2011;47:274-82. Medline:21440354 doi:10.1016/j.arbr.2011.01.004

31 Najafizadeh K. FADAEIZADEH L, Salek S. Prevalence and severity of asthmatic symptoms in rasht students: A report from ISAAC study. Tanaffos. 2008;7:40-6.

32 Martinez FD, Wright AL, Taussig LM, Holberg CJ, Halonen M, Morgan WJ, et al. Asthma and wheezing in the first six years of life. N Engl J Med. 1995;332:133-8. Medline:7800004 doi:10.1056/NEJM199501193320301

33 Neuman Å, Bergström A, Gustafsson P, Thunqvist P, Andersson N, Nordvall L, et al. Infant wheeze, comorbidities and school age asthma. Pediatr Allergy Immunol. 2014;25:380-6. Medline:24720853 doi:10.1111/pai.12223

34 Bjerg-Bäcklund A, Perzanowski M, Platts-Mills T, Sandström T, Lundbäck B, Rönmark E. Asthma during the primary school ages-prevalence, remission and the impact of allergic sensitization. Allergy. 2006;61:549-55. Medline:16629783 doi:10.1111/ j.1398-9995.2006.01027.x

35 Burr ML, Wat D, Evans C, Dunstan FD, Doull IJ. Asthma prevalence in 1973, 1988 and 2003. Thorax. 2006;61:296-9. Medline:16396947 doi:10.1136/thx.2005.045682

36 Del-Rio-Navarro B, Del Rio-Chivardi JM, Berber A, Sienra-Monge JJL, Rosas-Vargas MA, Baeza-Bacab M, editors. Asthma prevalence in children living in north Mexico City and a comparison with other Latin American cities and world regions. Allergy Asthma Proc. 2006;27:334-40. Medline:16948346 doi:10.2500/aap.2006.27.2880

37 Farrokhi S, Gheybi MK, Movahhed A, Dehdari R, Gooya M, Keshvari S, et al. Prevalence and risk factors of asthma and allergic diseases in primary schoolchildren living in Bushehr, Iran: phase I, III ISAAC protocol. Iran J Allergy Asthma Immunol. 2014;13:348-55. Medline:25150076 
38 Nga NN, Chai SK, Bihn TT, Redding G, Takaro T, Checkoway H, et al. ISAAC-based asthma and atopic symptoms among Ha Noi school children. Pediatr Allergy Immunol. 2003;14:272-9. Medline:12911504 doi:10.1034/j.1399-3038.2003.00043.x

39 Bechtold P, Ranzi A, Gambini M, Capelli O, Magrini N, Cavallini R, et al. Assessing paediatric asthma occurrence through dispensed prescription data and questionnaires. Eur J Public Health. 2013;23:873-8. Medline:22689383 doi:10.1093/eurpub/ cks066

40 Dell SD, Foty RG, Gilbert NL, Jerrett M, To T, Walter SD, et al. Asthma and allergic disease prevalence in a diverse sample of Toronto school children: Results from the Toronto Child Health Evaluation Questionnaire (T-CHEQ) Study. Can Respir J. 2010;17:e1-6. Medline:20186360 doi:10.1155/2010/913123

41 Ng Man Kwong G, Proctor A, Billings C, Duggan R, Das C, Whyte M, et al. Increasing prevalence of asthma diagnosis and symptoms in children is confined to mild symptoms. Thorax. 2001;56:312-4. Medline:11254824 doi:10.1136/thorax.56.4.312

42 Chhabra SK, Gupta CK, Chhabra P, Pal SR. Prevalence of bronchial asthma in schoolchildren in Delhi. J Asthma. 1998;35:2916. Medline:9661682 doi:10.3109/02770909809068220

43 Maitra A, Sherriff A, Strachan D, Team AS, Henderson J. Mode of delivery is not associated with asthma or atopy in childhood. Clin Exp Allergy. 2004;34:1349-55. Medline:15347366 doi:10.1111/j.1365-2222.2004.02048.x

44 Adetoun Mustapha B, Briggs D, Hansell A. Prevalence of asthma and respiratory symptoms in children in a low socio-economic status area of Nigeria. Int J Tuberc Lung Dis. 2013;17:982-8. Medline:23743319 doi:10.5588/ijtld.12.0434

45 Delpisheh A, Kelly Y, Rizwan S, Brabin BJ. Salivary cotinine, doctor-diagnosed asthma and respiratory symptoms in primary schoolchildren. Matern Child Health J. 2008;12:188-93. Medline:17557199 doi:10.1007/s10995-007-0229-9

46 Hermann C, Olivarius NDF, Høst A, Begtrup K, Hollnagel H. Prevalence, severity and determinants of asthma in Danish fiveyear-olds. Acta Paediatr. 2006;95:1182-90. Medline:16982487 doi:10.1080/08035250600582814

47 Mirzadeh M, Kooshesh M, Mirzaei M. Asthma and environmental factors in children. Acta Med Bulg. 2016;43:45-51.

48 Montefort S, Ellul P, Montefort M, Caruana S, Agius Muscat H. Increasing prevalence of asthma, allergic rhinitis but not eczema in 5-to 8-yr-old Maltese children (ISAAC). Pediatr Allergy Immunol. 2009;20:67-71. Medline:19154255 doi:10.1111/ j.1399-3038.2008.00746.x

49 Samoliński B, Sybilski AJ, Raciborski F, Tomaszewska A, Samel-Kowalik P, Walkiewicz A, et al. Prevalence of asthma in children, adolescents and young adults in Poland-results of the ECAP study. Alerg Astma Immun. 2009;14:27-34.

50 Whyatt RM, Perzanowski MS, Just AC, Rundle AG, Donohue KM, Calafat AM, et al. Asthma in inner-city children at 5-11 years of age and prenatal exposure to phthalates: the Columbia Center for Children's Environmental Health Cohort. Environ Health Perspect. 2014;122:1141-6. Medline:25230320 doi:10.1289/ehp.1307670

51 Yeh KW, Ou L-S, Yao T-C, Li-Chen C, Wen L, Jing-Long H. Prevalence and risk factors for early presentation of asthma among preschool children in Taiwan. Asian Pac J Allergy Immunol. 2011;29:120. Medline:21980826

52 Christiansen SC, Martin SB, Schleicher NC, Koziol JA, Mathews KP, Zuraw BL. Current prevalence of asthma-related symptoms in San Diego's predominantly Hispanic inner-city children. J Asthma. 1996;33:17-26. Medline:8621367 doi:10.3109/02770909609077759

53 Webber MP, Carpiniello KE, Oruwariye T, Appel DK. Prevalence of asthma and asthma-like symptoms in inner-city elementary schoolchildren. Pediatr Pulmonol. 2002;34:105-11. Medline:12112776 doi:10.1002/ppul.10146

54 Galassi C, De Sario M, Biggeri A, Bisanti L, Chellini E, Ciccone G, et al. Changes in prevalence of asthma and allergies among children and adolescents in Italy: 1994-2002. Pediatrics. 2006;117:34-42. Medline:16396858 doi:10.1542/peds.2004-2709

55 Abuekteish F, Alwash R, Hassan M, Daoud A. Prevalence of asthma and wheeze in primary school children in northern Jordan. Ann Trop Paediatr. 1996;16:227-31. Medline:8893953 doi:10.1080/02724936.1996.11747831

56 Malik G, Tagiyeva N, Aucott L, McNeill G, Turner SW. Changing trends in asthma in 9-12 year olds between 1964 and 2009. Arch Dis Child. 2011;96:227-31. Medline:21068081 doi:10.1136/adc.2010.189175

57 Branco PTBS, Alvim-Ferraz MCM, Martins FG, Ferraz C, Vaz LG, Sousa SIV. Impact of indoor air pollution in nursery and primary schools on childhood asthma. Sci Total Environ. 2020;745:140982. Medline:32736106 doi:10.1016/j.scitotenv.2020.140982

58 Martyn M, Weaver AL, Jacobson RM, Juhn YJ. Characterisation of the duration from onset of asthma symptoms to asthma disease. Ann Allergy Asthma Immunol. 2008;100:589-95. Medline:18592824 doi:10.1016/S1081-1206(10)60059-2

59 Marks GB, Mihrshahi S, Kemp AS, Tovey ER, Webb K, Almqvist C, et al. Prevention of asthma during the first 5 years of life: a randomised controlled trial. J Allergy Clin Immunol. 2006;118:53-61. Medline:16815138 doi:10.1016/j.jaci.2006.04.004

60 National Heart L, and Blood Institute. Expert Panel Report 3: Guidelines for the Diagnosis and Management of Asthma. 2007. 61 Global Initiative for Asthma. Global Strategy for Asthma Management and Prevention, 2020.

62 Chung KF, Wenzel SE, Brozek JL, Bush A, Castro M, Sterk PJ, et al. International ERS/ATS guidelines on definition, evaluation and treatment of severe asthma. Eur Respir J. 2014;43:343-73. Medline:24337046 doi:10.1183/09031936.00202013

63 Walters JA, Hansen E, Mudge P, Johns DP, Walters EH, Wood-Baker R. Barriers to the use of spirometry in general practice. Aust Fam Physician. 2005;34:201-3. Medline:15799676

64 Zaman K, Takeuchi H, El Arifeen S, Chowdhury HR, Baqui AH, Wakai S, et al. Asthma in rural Bangladeshi children. Indian J Pediatr. 2007;74:539-43. Medline:17595495 doi:10.1007/s12098-007-0104-0

65 Ogasawara H, Hashimoto H. Relationship between maternal communicative/critical health literacy and child's asthma symptoms: Results from a population-based survey in metropolitan Japan. Patient Educ Couns. 2020;103:999-1004. Medline:31813711 doi:10.1016/j.pec.2019.11.026

66 Matos SM, Jesus SR, Saldiva SR, Prado MS, D'Innocenzo S, Assis AM, et al. Overweight, asthma symptoms, atopy and pulmonary function in children of 4-12 years of age: findings from the SCAALA cohort in Salvador, Bahia, Brazil. Public Health Nutr. 2011;14:1270-8. Medline:21486522 doi:10.1017/S1368980011000462 
67 Bröms K, Norback D, Eriksson M, Sundelin C, Svardsudd K. Prevalence and co-occurrence of parentally reported possible asthma and allergic manifestations in pre-school children. BMC Public Health. 2013;13:764. Medline:23953349 doi:10.1186/14712458-13-764

68 Ferreira-Magalhães M, Sa-Sousa A, Morais-Almeida M, Pite H, Azevedo LF, Azevedo MI, et al. Asthma-like symptoms, diagnostic tests, and asthma medication use in children and adolescents: A population-based nationwide survey. J Asthma. 2016;53:26976. Medline:26444577 doi:10.3109/02770903.2015.1095926

69 Ochoa-Avilés C, Morillo D, Rodriguez A, Cooper PJ, Andrade S, Molina M, et al. Prevalence and risk factors for asthma, rhinitis, eczema, and atopy among preschool children in an Andean city. PLoS One. 2020;15:e0234633. Medline:32649729 doi:10.1371/journal.pone.0234633

70 José BP, Camargos PA, Cruz Filho AA, Correa Rde A. Diagnostic accuracy of respiratory diseases in primary health units. Rev Assoc Med Bras. 2014;60:599-612. Medline:25650863 doi:10.1590/1806-9282.60.06.021

71 Aaron SD, Vandemheen KL, FitzGerald JM, Ainslie M, Gupta S, Lemiere C, et al. Reevaluation of Diagnosis in Adults With Physician-Diagnosed Asthma. JAMA. 2017;317:269-79. Medline:28114551 doi:10.1001/jama.2016.19627

72 Pavord ID, Beasley R, Agusti A, Anderson GP, Bel E, Brusselle G, et al. After asthma: redefining airways diseases. Lancet. 2018;391:350-400. Medline:28911920 doi:10.1016/S0140-6736(17)30879-6 